\title{
STUDY OF GLUCOSE TOLERANCE IN CHILDREN WITH TRANSFUSION DEPENDENT THALASSEMIA AND ITS CORRELATION WITH SERUM FERRITIN
}

\author{
Swati Mohan Gadappa1, Manas Kumar Behera²
}

${ }_{1}^{1}$ Associate Professor, Department of Paediatrics, Smt. Kashibai Navale Medical College and General Hospital, Pune.

2 Professor \& HOD, Department of Paediatrics, Smt. Kashibai Navale Medical College and General Hospital, Pune.

\section{ABSTRACT}

\section{BACKGROUND}

Thalassemia Major is the most common transfusion dependent anaemia in children causing long-term effects due to iron overload. The aim of this study is to determine the prevalence of glucose intolerance and diabetes mellitus in multi-transfused children with Thalassemia Major and to determine their correlation with clinical and biochemical parameters of iron overload.

\section{RESEARCH DESIGN AND METHODS}

Children [4-11 yrs.] with Transfusion Dependent Thalassemia major attending a tertiary care hospital were subjected to Oral glucose tolerance test and their Serum ferritin and Blood glucose levels were determined. Potential risk factors were identified using $t$ test, $X^{2}$ test and Fisher's exact test. A two-tailed $P$ value of $<0.05$ was considered to be statistically significant.

\section{RESULTS}

Total 25 children [4-11 yrs. age; Mean age=6.02 yrs.] with 12 Males and 13 Females were studied. Mean serum ferritin was 2178.6 $\mu \mathrm{g} / \mathrm{L}$. Mean BMI was 14.47. Mean Hb over 2 yrs. was $7.05 \mathrm{~g} / \mathrm{dL}$. Severe Hepatomegaly and severe Splenomegaly was noted in $24 \%$ and $32 \%$ of children respectively; $92 \%$ children were on irregular oral chelation therapy. Diabetes mellitus was not seen in our study. Impaired Glucose Tolerance was detected in [ $\mathrm{n}=04] 16 \%$ patients and Impaired Fasting Glucose was detected in [n=03] $12 \%$ patients. The significant clinical characteristics associated with the diagnosis of impaired glucose metabolism were Mean Haemoglobin over past 2 yrs. Higher Serum Ferritin, amount of Blood transfusion units received and duration of chelation therapy.

\section{KEYWORDS}

Impaired Glucose Tolerance, Ferritin, Iron Overload.

HOW TO CITE THIS ARTICLE: Gadappa SM, Behera MK. Study of glucose tolerance in children with transfusion dependent thalassemia and its correlation with serum ferritin. J. Evolution Med. Dent. Sci. 2016;5(35):1959-1962, DOI: $10.14260 /$ jemds/2016/463

\section{INTRODUCTION}

Beta Thalassemia Major is the most common transfusion dependent anaemia and haemoglobinopathy seen in India. The cumulative gene frequency of haemoglobinopathies in India is $4.2 \%$. With a population of over one billion and a birth rate of 28 per thousand, there are over 42 million carriers and over 12,000 infants are born each year with a major and clinical significant haemoglobinopathy.1,2 The use of regular, frequent blood transfusions in thalassemia major has improved the span and quality of life of the patients. But it leads to chronic iron overload, which frequently causes endocrine problems, especially diabetes mellitus.

The reported incidence of impaired glucose tolerance in thalassemia major is $4-24 \% 0^{3-9}$ and that of diabetes mellitus is $0-26 \% .^{3-11}$ Mechanism of Glucose intolerance in transfusion dependent anaemia is unknown, but is attributed mainly due to insulin deficiency resulting from the toxic effects of iron deposited in the pancreas and from insulin resistance. Persistent insulin resistance along with a progressive reduction in circulating insulin levels may lead to glucose

Financial or Other, Competing Interest: None.

Submission 02-04-2016, Peer Review 15-04-2016,

Acceptance 18-04-2016, Published 29-04-2016.

Corresponding Author:

Dr. Swati Mohan Gadappa,

601/B3, Runwal Seagull Township,

Handewadi Road, Hadapsar,

Pune-411028.

E-mail: swatigadappa@yahoo.co.in

DOI: $10.14260 /$ jemds/2016/463 intolerance and overt diabetes.12 early identification of IGT will decrease life-threatening presentation with diabetic ketoacidosis.

Screening and detecting early signs of overt diabetes would help in preventing related acute and long-term complications and establishing early glycaemic control in diabetic children with Thalassemia Major.

\section{AIMS AND OBJECTIVES}

1. To study the prevalence of glucose intolerance and diabetes mellitus in multi-transfused children with Thalassemia Major.

2. To determine their correlation with clinical and biochemical parameters of iron overload like serum ferritin, growth retardation, amount of blood transfusions received, hepatosplenomegaly and duration of chelation therapy.

\section{MATERIALS AND METHODS}

This study was conducted in Department of Paediatrics of a tertiary care centre over a period of 1 year from December 2014 to November 2015 after obtaining the requisite permission of the Ethics Committee of the hospital. All Paediatric patients with Thalassemia major receiving blood transfusions in Department of Paediatrics for more than 3 years' duration were included in the study. Children with heart disease, infections, any chronic systemic illness, infections secondarily affecting the liver, recent history of mumps, children on steroid therapy and those with diabetes mellitus diagnosed previously and those with other transfusion 
dependent anaemia were excluded. Informed consent was obtained from parents/guardians of all patients included in the study. Age, sex, height, weight, mean pre-transfusion $\mathrm{Hb}$ over past 2 years' duration and volume of blood transfusion, age at the start of chelation therapy, duration of chelation, serum ferritin in last 6 months, HBsAg and family history of diabetes were noted.

\section{Definitions and Oral Glucose Tolerance Test}

In this study, we used the World Health Organization's definition of diabetes. ${ }^{13}$ If patients were not diabetic, an Oral Glucose Tolerance Test (OGTT) was performed in the morning after an overnight fast as recommended by the National Diabetes Data Group. ${ }^{14}$

\section{Intervention Plan}

All patients were informed to take normal diet 3 days prior to the test and were asked to be fasting for $8 \mathrm{hrs}$. prior to testing. IV sample for Fasting Plasma glucose levels and Serum Ferritin were taken.

\section{Oral Glucose Tolerance Test [OGTT]}

Glucose was given orally in a dose of $1.75 \mathrm{~g} / \mathrm{kg}$ up to a maximum of $75 \mathrm{~g}$ and blood sample were obtained at $120 \mathrm{~min}$. for measurement of plasma glucose.

- Diagnosis of diabetes mellitus and glucose intolerance were made by WHO criteria. Impaired Fasting Glucose (IFG) is diagnosed if fasting plasma glucose $>110 \mathrm{mg} / \mathrm{dL}$ and $</=125 \mathrm{mg} / \mathrm{dL}(6.1-7.0 \mathrm{mmol} / \mathrm{L})$.

- Impaired glucose tolerance test is diagnosed if the $2 \mathrm{hr}$. post glucose plasma glucose was $>140 \mathrm{mg} / \mathrm{dL}$ and $</=200$ $\mathrm{mg} / \mathrm{dL}$ (7.8-11.1 mmol/L).

- Diabetes is diagnosed if the fasting plasma glucose was $>/=126 \mathrm{mg} / \mathrm{dL}(7.0 \mathrm{mmol} / \mathrm{L})$ and 2-hour post glucose plasma glucose $>/=200 \mathrm{mg} / \mathrm{dL}(11.1 \mathrm{mmol} / \mathrm{L})$.

- Normoglycaemic is diagnosed if fasting plasma glucose is $</=110 \mathrm{mg} / \mathrm{dL}$.

\section{STATISTICAL ANALYSIS}

Differences between patients with and without abnormal glucose tolerance were tested with the independent ' $t$ ' test, $\chi$ test, and Fisher's exact test to identify the potential risk factors. Stepwise logistic regression analysis done to select the independent risk factors that best predicted abnormal glucose tolerance. A two-tailed $\mathrm{P}$ value of $<0.05$ was considered to be statistically significant.

\section{RESULTS}

Total 25 patients were studied with 12 Males and 13 Females [M:F 0.92:1]. The age of children varied from 4-11 yrs. with mean age of $6.02 \mathrm{yrs}$. The mean age of diagnosis and receiving $1^{\text {st }}$ blood transfusion was 0.89 yrs. The mean haemoglobin over the past 2 years was $7.05 \mathrm{~g} / \mathrm{dL}[5-9 \mathrm{mg} / \mathrm{dL}$. The mean duration of transfusion was 5.06 yrs. [3-10.08 yrs.]; $92 \%$ children were on irregular oral chelation therapy. The average duration of receiving chelation was 3.29 yrs. Massive hepatomegaly [ $>6 \mathrm{~cm}$ below costal margin] was seen in $24 \%$ and massive splenomegaly [ $>6 \mathrm{~cm}$ below costal margin] was noted in $32 \%$ of patients.

Mean BMI was 14.47 with a range of $12.94-17.75$ in males and 12.45-15.41 in females. Clinically, these children had stunting in [n=08] 32\%, whereas wasting was noted in $[n=12] 48 \%$ children. Of the children with glucose intolerance [07/25], 05 patients [71.4\%] had wasting and 02 [28.7\%] had stunting. The correlation between Glucose intolerance and wasting was not significant $[p=0.144]$. Similarly, the correlation between Glucose intolerance and Stunting was not significant [ $\mathrm{p}=0.819]$.

The mean serum ferritin was $2178.6 \mu \mathrm{g} / \mathrm{L}$ [range 97.50 7058]. The blood glucose levels at 0 minutes were ranging from $71-139 \mathrm{mg} / \mathrm{dL}$ [mean $100.92 \mathrm{mg} / \mathrm{dL}$ ]. Blood glucose levels at 120 minutes were ranging from $74-198 \mathrm{mg} / \mathrm{dL}$ [mean $128.80 \mathrm{mg} / \mathrm{dL}]$. We found no cases of diabetes mellitus in this study. However, Impaired Fasting Glucose [IFG] was noted in 03 patients [12\%], while Impaired Glucose Tolerance [IGT] was noted in 04 patients [16\%] in our study. Thus, $72.0 \%$ of the thalassemic children were normoglycaemic.

Correlation between Serum Ferritin and mean Hb over 2 years is not significant $[\mathrm{p}=0.080]$. Correlation between Serum Ferritin and BSL at 0 minutes was significant $[\mathrm{r}=0.489$, $\mathrm{p}=0.007]$. However, the correlation of serum Ferritin to BSL at $120 \mathrm{~min}$. was not significant $[\mathrm{r}=0.301, \mathrm{p}=0.072]$. Thus, those patients with high Serum Ferritin levels had higher Fasting blood glucose levels.

Comparing patients who were normoglycaemic $[\mathrm{n}=18]$ with patients who had IFG or IGT [n=07] showed statistically significant difference in the OGTT 0 mins. [14.62/10.29 SD; $\mathrm{p}=0.001]$ and OGTT 120 mins. [27.86/14.62SD; $\mathrm{p}=0.002]$.

\begin{tabular}{|c|c|c|c|c|c|}
\hline & Glucose Tolerance & $\mathbf{N}$ & Mean & Std. Deviation & Sig [2-Tailed] \\
\hline \multirow{2}{*}{ Duration of Transfusion } & IFG / IGT & 7 & 5.82 & 2.17907 & \multirow{2}{*}{0.206} \\
\hline & Normoglycaemics & 18 & 4.9033 & 1.30507 & \\
\hline \multirow{2}{*}{ Number of Transfusions Received } & IFG / IGT & 7 & 46.86 & 17.893 & \multirow{2}{*}{0.197} \\
\hline & Normoglycaemics & 18 & 37.22 & 15.653 & \\
\hline \multirow{2}{*}{ Serum Ferritin } & IFG / IGT & 7 & 2938.714 & 1454.5228 & \multirow{2}{*}{0.158} \\
\hline & Normoglycaemics & 18 & 1882.99 & 1679.42184 & \\
\hline \multirow{2}{*}{ Average Haemoglobin Over Past 2 years } & IFG / IGT & 7 & 7.4857 & 1.25224 & \multirow{2}{*}{0.22} \\
\hline & Normoglycaemics & 18 & 6.8833 & 1.0025 & \\
\hline \multirow{2}{*}{ Present Haemoglobin } & IFG / IGT & 7 & 8.0857 & 1.42177 & \multirow{2}{*}{0.303} \\
\hline & Normoglycaemics & 18 & 7.5889 & 0.89501 & \\
\hline \multirow{2}{*}{ OGTT 0 Minutes } & IFG / IGT & 7 & 114.57 & 14.627 & \multirow{2}{*}{0.001} \\
\hline & Normoglycaemics & 18 & 95.61 & 10.291 & \\
\hline \multirow{2}{*}{ OGTT 120 Minutes } & IFG / IGT & 7 & 160.71 & 27.861 & \multirow{2}{*}{0.002} \\
\hline & Normoglycaemics & 18 & 109.44 & 14.626 & \\
\hline \multirow{2}{*}{ Chelation Duration } & IFG / IGT & 7 & 3.5943 & 1.98991 & \multirow{2}{*}{0.567} \\
\hline & Normoglycaemics & 16 & 3.16 & 1.486 & \\
\hline
\end{tabular}


In children with Impaired Fasting Glucose [IFG], significant correlation was noted between mean $\mathrm{Hb}$ over 2 yrs. and present $\mathrm{Hb}$ [1.000, p=0.006]. Serum ferritin had no significant correlations. No correlation was noted between BMI and any transfusion parameters or serum ferritin. In children with Impaired Glucose Tolerance [IGT], duration of chelation correlated significantly with duration of transfusion [0.967, $\mathrm{p}=0.016$ ] and number of transfusions [0.958, $\mathrm{p}=0.021$ ]. Duration of transfusion also correlated well with BMI [0.913, $\mathrm{p}=0.044]$. In normoglycaemic children, serum ferritin had significant correlation with chelation duration [-0.534, $\mathrm{p}=0.017]$ and Mean Hb over 2 yrs. [-0.567; $\mathrm{p}=0.007]$. BMI correlated well with duration of transfusion [0.913, $\mathrm{p}=0.044]$.

\section{DISCUSSION}

Patients with multi-transfused thalassemia major may develop severe endocrine complications due to iron overload. The anterior pituitary is particularly sensitive to iron overload, which disrupts hormonal secretion resulting in hypogonadism, short stature, acquired hypothyroidism and hypoparathyroidism. Glucose intolerance in adolescence and diabetes mellitus later in life are also frequent complications mainly due to iron overload, chronic liver disease and genetic predisposition. ${ }^{15}$ The effect of iron overload on glucose metabolism is probably due to iron deposition in liver and pancreas causing increased insulin resistance or decreased insulin production leading to glucose intolerance and further diabetes mellitus.

Iron overload of tissue which is fatal with or without transfusion, if not prevented or adequately treated is the most important complication of $b$-thalassemia and is a major focus of management. ${ }^{16}$ Although, most clinical manifestations of iron loading do not appear until the second decade of life in patients with inadequate chelation, evidence from serial liver biopsies in very young patients indicates that the deleterious effects of iron are initiated much earlier than this. After approximately one year of transfusions, iron begins to be deposited in parenchymal tissues causing toxic effects. ${ }^{17}$

We found no patients with frank diabetes mellitus as opposed to the reported incidence of $0-26 \% \cdot^{3-11}$ of diabetes mellitus, probably due to small sample size. However, $28 \%$ of our patients had impaired glucose tolerance as compared to 4$24 \% .^{3-7,9}$ in other studies. The higher incidence can be attributed to irregular transfusion and reduced compliance to chelation therapy in low socioeconomic patients in our study. A retrospective study done in 1861 patients of thalassemia major patients has shown 18.1 years, as the mean age of onset of diabetes. ${ }^{8}$ Arrigo et al have demonstrated the age of onset of diabetes in thalassemics to be after 18 years. ${ }^{10}$ The low incidence in other studies could be due to the advancement in the age of occurrence of diabetes in thalassemics over the years. ${ }^{8,18}$ which can be attributed partly to iron chelation therapy. 8,19

Persistent insulin resistance along with a progressive reduction in circulating insulin levels may lead to glucose intolerance and overt diabetes. However, study by Suvarna et al demonstrated that the non-diabetic thalassemics showed higher fasting plasma insulin levels with increased insulin resistance index and normal plasma glucose suggesting the presence of insulin resistance before the onset of frank impaired glucose tolerance test or diabetes. ${ }^{20}$
The high insulin level is probably in compensation for the insulin resistance in an attempt to maintain euglycaemia. A similar increase in the insulin levels before the advent of impaired glucose tolerance test and diabetes was also demonstrated in a study by Flynn et al. ${ }^{6}$ Due to financial constraints, we could not perform a simultaneous fasting insulin levels in our study.

Serum ferritin had significant correlation with fasting BSL in all our patients. Serum ferritin concentration, a marker for hepatic iron concentration, was found to be an independent risk factor in study by Chern et al. ${ }^{9}$ Serum ferritin has been considered to be a component of insulin resistance syndrome in epidemiological studies. ${ }^{21}$ Elevated iron stores were positively associated with the prevalence of the metabolic syndrome and with insulin resistance. Studies have indicated that when the serum ferritin level is $<2,500 \mu \mathrm{g} / \mathrm{L}$, the incidence of diabetes is reduced.16,19,22 On the contrary, we noted that two patients with IGT and one patient with IFG had serum ferritin levels of 1475, 2370 and $1200 \mu \mathrm{g} / \mathrm{L}$, respectively. The ferritin levels of remaining children with IGT were $3831 \mu \mathrm{g} / \mathrm{L}$ and $2600 \mu \mathrm{g} / \mathrm{L}$ and those of IFG were 5295 $\mu \mathrm{g} / \mathrm{L}$ and $3800 \mu \mathrm{g} / \mathrm{L}$. The mean serum ferritin level was 2178 $\mu \mathrm{g} / \mathrm{L}$ in our study and majority of our study population [72\%] were normoglycaemic.

Hence, although serum ferritin plays an important role in the genesis of insulin resistance, we believe that the development of diabetes might be complicated by other baseline conditions. It is still unclear whether diabetes in $\beta$ thalassemia major is related to genetic factors. ${ }^{8,23}$ None of our patients in this study had a family history of diabetes. In our study, the significant clinical characteristics associated with the diagnosis of impaired glucose metabolism were mean haemoglobin over past 2 yrs. Higher serum ferritin, amount of blood transfusion units received and duration of chelation therapy. Jaruratanasirikul et al demonstrated the clinical characteristics of thalassemic patients who developed impaired glucose tolerance were wasting, stunting, higher ferritin levels, splenectomy and lower AUC insulin. ${ }^{24}$ Thus compliance to chelation therapy, regular transfusions to maintain mean $\mathrm{Hb} 9-10 \mathrm{~g} / \mathrm{dL}$ is desirable to prevent onset of glucose intolerance.

We did not find significant correlation of stunting and wasting in glucose intolerant children in comparison with normoglycaemic children. Diabetes has been observed to develop shortly after an episode of acute viral hepatitis in thalassemic patients. ${ }^{8}$ and chronic hepatitis $C$ infection was considered to have a diabetogenic effect. ${ }^{25}$ Our study did not have any children with acute viral hepatitis. Hepatitis B antigen was negative in all patients. However, Hepatitis $C$ demonstration could have given additional information on being a possible risk factor.

Diabetic ketoacidosis has been reported to be the presenting manifestation of diabetes in $13.8 \% .12-31.1 \% .^{9}$ of thalassemia major. This life-threatening complication can be avoided through creating awareness and active surveillance for the occurrence of impaired glucose tolerance and diabetes in multi-transfused thalassemic children. Moreover, thalassemic patients with clinical diabetes are at a high risk for other complications like endocrine (Especially Thyroid Dysfunctions, Hypogonadism, Pubertal delay, etc.) or cardiac or both and should be strictly monitored for these. 12 
Impaired glucose tolerance develops few months to five years before development of diabetes. Hence, early detection is imperative for better quality of life for multi-transfused children. Thus compliance to chelation therapy, regular transfusions to maintain mean $\mathrm{Hb}$ 9-10 g/dL, appropriate screening is desirable to prevent onset of diabetes mellitus.

\section{CONCLUSION}

Regular blood transfusions, good compliance to chelation therapy, regular monitoring of serum ferritin and periodic blood sugar levels will help in prevention of diabetes in multitransfused children with thalassemia major.

Timely screening for Hepatitis C, liver function tests, growth monitoring, oral glucose tolerance test can prevent long-term comorbidities in these children.

\section{REFERENCES}

1. MadhulikaKabra PSN Menon. The challenge of haemoglobinopathies in India. The National Medical Journal of India 1999;12(5):198-201.

2. Agarwal MB. The burden of haemoglobinopathies in India. JAPI 2005;53:1017-8.

3. Torres FA, Bonduel M, Sciuccati G, et al. Beta thalassemia major in Argentina. Medicina 2002;62(2):124-34.

4. El-Hazmi MA, Al-Swailem A, Al-Fawaz I, et al. Diabetes mellitus in children suffering from beta-thalassaemia. J Trop Paediatr 1994;40(5):261-6.

5. Khalifa AS, Salem M, Mounir E, et al. Abnormal glucose tolerance in egyptian beta thalassemic patients: possible association in genotyping. Paediatr Diabetes 2004;5(3):126-32.

6. Flynn DM, Fairney A, Jackson D, et al. Hormonal changes in thalassaemia major. Arch Dis Child 1976;51(11):828-36.

7. Cario H, Holl RW, Debatin KM, et al. Insulin sensitivity and beta-cell secretion in thalassaemia major with secondary haemo-chromatosis: assessment by oral glucose tolerance test. Eur J Paediatr 2003;162(3):139-46.

8. Italian working group on endocrine complications in nonendocrine diseases. Multi centre study on prevalence of endocrine complications in thalassaemia major. Clin Endocrinol 1995;42(6):581-6.

9. Jimmy PS Chern, Kai-Hsin Lin, Meng-Yao Lu, et al. Abnormal glucose tolerance in transfusion-dependent $\beta$ thalassemic patients. Diabetes Care 2001;24(5):850-4.

10. Arrigo T, Crisafulli G, Meo A, et al. Glucose tolerance, insulin secretion and peripheral sensitivity in thalassaemia major. J Paediatr Endocrinol Metab 1998;11(3):863-6.
11. Rodriguez GC, Ortega AJJ, Alonso JL, et al. Evaluation of the efficacy of chelation therapy with deferoxamine in patients with thalassemia major. Med Clin 1994;102(19):721-4.

12. Sanctiz VD, Zurlo MG, SENESI E, et al. Insulin dependent diabetes in thalassemia. Arch Dis Child 1988;63(1):58-62.

13. World Health Organization: Diabetes mellitus: report of a WHO study group. Geneva, World Health Org 1985;727:1113.

14. National diabetes data group. Classification and diagnosis of diabetes mellitus and other categories of glucose intolerance. Diabetes 1979;28(12):1039-57.

15. Toumba M, Sergis A, Kanaris C, et al. Endocrine complications in patients with thalassaemia major. Paediatric Endocrinology Reviews 2007;5(2):642-8.

16. Olivieri NF, Brittenham GM. Iron-chelating therapy and the treatment of thalassemia. Blood 1997;89(3):739-61.

17. Risdon RA, Flynn DM, Barry M. The relation between liver iron concentration and liver damage in transfusional iron overload in thalassaemia and the effect of chelation therapy. Gut 1973;14(5):421.

18. Gamberini MR, Fortini M, Gilli G, et al. Epidemiology and chelation therapy effects on glucose homeostasis in thalassaemic patients. J Paediatr Endocrinol Metab 1998;11(3):867-9.

19. Brittenham GM, Griffith PM, Nienhuis AW, et al. Efficacy of deferoxamine in preventing complications of iron overload in patients with thalassemia major. $N$ Engl J Med 1994;331:567-73.

20. Jyoti Suvarna, Hemraj Ingle, Deshmukh CT. Insulin resistance and beta cell function in chronically transfused patients of thalassemia major. Indian Paediatrics 2006;43(5):393-400.

21. Fernandez-Real JM, Ricart-Engel W, Arroyo E, et al. Serum ferritin as a component of the insulin resistance syndrome. Diabetes Care 1998;21(1):62-8.

22. Olivieri NF, Nathan DG, MacMillan JH, et al. Survival in medically treated patients with homozygous betathalassemia. N Engl J Med 1994;331(9):574-8.

23. Lin KH, Lin KS, Feig SA. Marrow transplantation for thalassemia. Bone Marrow Transplant 1986;1(2):115-20.

24. Jaruratanasirikul S, Chareonmuang R, Wongcharn-chailert $\mathrm{M}$, et al. Prevalence of impaired glucose metabolism in beta-thalassemic children receiving hyper transfusions with a suboptimal dosage of iron-chelating therapy. Eur J Paediatr 2008;167(8):873-6.

25. Labropoulou-Karatza C, Goritsas C, Fragopanagou H, et al. High prevalence of diabetes mellitus among adult bthalassemic patients with chronic hepatitis C. Eur J Gastroenteol Hepatol 1999;11(9):1033-6. 